\title{
In vitro effects of interleukin (IL)-1 beta inhibition on the epithelial-to-mesenchymal transition (EMT) of renal tubular and hepatic stellate cells
}

\author{
Valentina Masola ${ }^{1 \dagger}$, Amedeo Carraro ${ }^{2 \dagger}$, Simona Granata ${ }^{1}$, Lorenzo Signorini ${ }^{1}$, Gloria Bellin ${ }^{1}$, Paola Violi \\ Antonio Lupo ${ }^{1}$, Umberto Tedeschi ${ }^{2}$, Maurizio Onisto ${ }^{3}$, Giovanni Gambaro ${ }^{4}$ and Gianluigi Zaza ${ }^{*}$ (D)
}

\begin{abstract}
Background: The epithelial to mesenchymal transition (EMT) is a multi-factorial biological mechanism involved in renal and hepatic fibrosis and the IL-1 beta has been assumed as a mediator of this process although data are not exhaustive. Therefore, the aim of our study was to evaluate the role of this cytokine in the EMT of renal proximal tubular epithelial cells (HK-2) and stellate cells (LX-2) and the protective/anti-fibrotic effect of its inhibition by Canakinumab (a specific human monoclonal antibody targeted against IL-1 beta).
\end{abstract}

Methods: Both cell types were treated with IL-1 beta $(10 \mathrm{ng} / \mathrm{ml})$ for 6 and $24 \mathrm{~h}$ with and without Canakinumab $(5 \mathrm{\mu g} / \mathrm{ml})$. As control we used TGF-beta $(10 \mathrm{ng} / \mathrm{ml})$. Expression of EMT markers (vimentin, alpha-SMA, fibronectin) were evaluated through western blotting and immunofluorescence. Genes expression for matrix metalloproteinases (MMP)-2 was measured by Real-Time PCR and enzymatic activity by zymography. Cellular motility was assessed by scratch assay.

Results: IL-1 beta induced a significant up-regulation of EMT markers in both cell types and increased the MMP-2 protein expression and enzymatic activity, similarly to TGF-beta. Moreover, IL-1 beta induced a higher rate of motility in HK-2. Canakinumab prevented all these modifications in both cell types.

Conclusions: Our results clearly demonstrate the role of IL-1 beta in the EMT of renal/stellate cells and it underlines, for the first time, the therapeutic potential of its specific inhibition on the prevention/minimization of organ fibrosis.

Keywords: Epithelial to mesenchymal transition, Canakinumab, Fibrosis, Liver, Kidney, Interleukin 1 beta

\section{Background}

Renal and hepatic fibrosis are characterized by the accumulation of extra-cellular matrix (ECM), and both represent the final common pathway of a wide variety of renal and liver diseases. In this context, epithelial-mesenchymal transition (EMT) has a central role.

\footnotetext{
*Correspondence: gianluigi.zaza@univr.it

†Valentina Masola and Amedeo Carraro contributed equally to this work 1 Renal Unit, Department of Medicine, University-Hospital of Verona, Piazzale A. Stefani 1, 37126 Verona, VR, Italy

Full list of author information is available at the end of the article
}

During EMT epithelial cells lose their junctions, the apical-basal polarity and their epithelial regular shape acquiring high motility, the ability to produce ECM, and apoptosis resistance [1-3]. During the trans-differentiation, these cells undergo a reprogramming of gene expression with down-regulation of epithelial markers, up-regulation of mesenchymal markers (Vimentin, $\alpha$-SMA) and ECM components (type I collagen and Fibronectin) [4].

This process is regulated by a complex intracellular network, where specific transcription factors (SNAIL, SLUG, ZEB1), surface molecules, cytoskeleton proteins 
and matrix metalloproteinases (MMP-2, MMP-9) are involved, as well as several miRNAs [1]. Numerous biological elements are able to induce EMT, such as growth factors (e.g., epidermal growth factor, fibroblast growth factor, connective tissue growth factor, platelet-derived growth factor, insulin-like growth factor), integrins, transforming growth factor $\beta$ (TGF- $\beta$ ) e cytokines (e.g., TNF- $\alpha$, IL-4, IL-13) $[5,6]$.

However, in the biological mechanisms underlie both renal and liver fibrosis, IL- $1 \beta$, a pro-inflammatory mediator derived mainly by macrophages, endothelial cells, epithelial cells and fibroblasts seems to have a central role. Major effects of the IL-1 beta include: (1) Endothelial cells activation; (2) Neutrophils diapedesis induction; (3) Enhancement of lymphocytes ( $\mathrm{T}$ and B) cytokines synthesis [7].

Under physiological conditions, tissues do not express IL- $1 \beta$ but it can be rapidly induced through the activation of pattern recognition receptors (e.g. toll-like receptors, TLR) activated by pathogens and damaged cells products [8].

IL-1 $\beta$ is first synthesized as biologically inactive proIL- $1 \beta$ and then processed into biologically active IL-1 $\beta$ through a caspase-1-dependent proteolysis $[9,10]$. Since CASPASE- 1 is usually inactive, an effective IL- $1 \beta$ secretion is finely regulated and depends on inflammasome activation, a complex constituted by NOD-like receptors, ASC and the CASPASE-1 itself [11]. Moreover, IL- $1 \beta$ can be activated through mast cell-derived proteases and neutrophils-derived elastase and cathepsin-G $[12,13]$.

This cytokine exerts some pro-fibrotic effects by inducing TGF- $\beta$ synthesis $[14,15]$ pro-inflammatory cytokines and fibrosis markers (i.e. FIBRONECTIN, $\alpha$-SMA) release [15], and activating fibroblasts proliferation [16, 17]. Interestingly, fibroblasts seem to increase their sensitivity to this interleukin over the time, as shown in cells from fibrotic kidneys $[16,18]$.

Moreover, IL-1 $\beta$ expression can be correlated with the degree of glomerulosclerosis [19-24] and, as demonstrated in several animal models, its inhibition can slow down the progression of chronic renal damage. Furthermore, the administration of an IL-1R antagonist completely abrogated interstitial fibrosis/tubular atrophy (IF/ TA) [25-27]. In a murine model of unilateral ureteral obstruction, IL- $1 \beta$ has demonstrated itself to be essential for synthesis and release of TGF- $\beta$ and its downstream effects including the expression of connective tissue growth factor (CTGF) and type I COLLAGEN synthesis [28].

Also in hepatic tissue, IL-1 $\beta$ is an important and early mediator of fibrosis. It is induced within $1 \mathrm{~h}$ after the pro-fibrotic insult, and, stimulating MMP-9 expression, mediates the ECM degradation within Disse's space leading to collapse of hepatic sinusoids [29-32]. In addition, IL-1 $\beta$ promotes survival of activated hepatic stellate cells (HSCs) [33]. As a consequence, IL-1R antagonism showed itself to have a protective anti-fibrotic role also in hepatic tissues [31, 34].

On these bases, several IL-1 targeting agents (such as Canakinumab, Anakinra and Rilonacept) have been developed and introduced in clinical practice that interfere with the bond between IL-1 $\beta$, its receptor (IL-1R), and the accessory protein of this receptor (IL-1RacP) [35].

Among them, Canakinumab (ACZ885, Ilaris $^{\circledR}$, Novartis), a human monoclonal anti-body (mAb) targeting IL-1 $\beta$, may represent a new pharmacological tool to treat and minimize complications following several chronic degenerative diseases [36-39].

Canakinumab presents some interesting characteristics, which make it profitable with respect to other IL- $1 \beta$ inhibitors: it is highly specific for IL-1 $\beta$, whereas Anakinra and Rilonacept act against both IL- $1 \alpha$ and $\beta$. Furthermore, it has a long half-life, which allows low-dose and long-lasting administration [40].

Therefore, the aim of this study has been to evaluate the effect of Canakinumab on IL-1 $\beta$-induced EMT in kidney epithelial and hepatic stellate cells. This could reinforce the available literature regarding its potential use in clinical practice.

\section{Materials and methods}

\section{Cellular cultures and treatments}

Renal proximal tubular epithelial cells (HK-2) was purchased from American Type Culture Collection (ATCC) and human stellate hepatic cells (LX-2) was obtained from Merck Millipore (Germany). Both cell lines were cultured in DMEM-High Glucose (EuroClone) (17.5 mM glucose) with $10 \%$ fetal bovine serum (Biochrom AG), L-glutamine $(2 \mathrm{mM})$, penicillin $(100 \mathrm{U} / \mathrm{ml})$ and streptomycin $(100 \mu \mathrm{g} / \mathrm{ml})$ at $37^{\circ} \mathrm{C}$ in a humidified atmosphere with $5 \% \mathrm{CO}_{2}$. After reaching a confluence of about $80 \%$, serum was removed for $24 \mathrm{~h}$ (starvation) and subsequently treated with TGF- $\beta$ (10 ng/ml) or IL- $1 \beta$ (10 ng/ $\mathrm{ml})[41,42]$ in the presence or absence of Canakinumab $(5 \mu \mathrm{g} / \mathrm{ml})$.

\section{Migration assay}

HK-2 cells monolayer was incised with a sterile pipette tip to create a scratch and washed with PBS to remove non-adherent cells. Then it is incubated with culture media containing TGF- $\beta$, IL- $1 \beta$ in presence or absence of Canakinumab. The cells were photographed at different time points and the scratch area was measured in each photo to obtain a mean value. The migration was reported as the difference (in $\mathrm{mm}^{2}$ ) between the scratch 
area dimensions observed at baseline and after $24 \mathrm{~h}$. Each experimental condition was tested in triplicate.

\section{Gene expression analysis}

Both cell types were treated with TGF- $\beta$ (10 ng/ml) or IL-1 $\beta(10 \mathrm{ng} / \mathrm{ml})$ in the presence or absence of Canakinumab $(5 \mu \mathrm{g} / \mathrm{ml})$ for $6 \mathrm{~h}$. Then, total RNA was extracted with Trizol reagent (Invitrogen), following the manufacturer's instructions. Quantity and quality of RNA were checked using the Nanodrop spectrophotometer (EuroClone). Total RNA was reverse-transcribed into cDNA using the reverse transcriptase SuperScript II (Invitrogen). Real Time-PCR reactions were performed with the ABI-Prism 7500 using Power SYBR Green Master Mix 2 (Applied Biosystem) and specific primers for $M m p-2$ and Glyceraldehyde-3-phosphate dehydrogenase (Gapdh). The primers are listed in Table 1.

The comparative $\mathrm{Ct}$ method $(\Delta \Delta \mathrm{Ct})$ was used to quantify gene expression, and the relative quantification was calculated as $2^{-\Delta \Delta C t}$. The GAPDH gene amplification was used as a reference standard to normalize the target signal. Melting curve analysis was used to confirm the specificity of amplification.

\section{Zymography}

In order to evaluate the activity of MMP- 2 in the conditioned media of HK-2 and LX-2 cells we used a zymography on a gelatin substrate. Conditioned media were prepared by incubating subconfluent cells in serum-free medium with TGF- $\beta(10 \mathrm{ng} / \mathrm{ml})$ or IL- $1 \beta(10 \mathrm{ng} / \mathrm{ml})$ in the presence or absence of Canakinumab $(5 \mu \mathrm{g} / \mathrm{ml})$ for $24 \mathrm{~h}$. Equal amounts of conditioned media were processed in SDS-PAGE under non-reducing conditions on $10 \%$ SDS-polyacrylamide gels co-polymerized with $0.5 \%$ gelatin, which is a substrate for gelatinases. After electrophoresis, gels were washed twice for $30 \mathrm{~min}$ in $2.5 \%$ Triton X-100 at room temperature to remove SDS, then equilibrated for $30 \mathrm{~min}$ in collagenase buffer. Finally, these gels were incubated overnight with a new collagenase buffer at $37{ }^{\circ} \mathrm{C}$. After incubation, the gels were stained in 0.1\% Coomassie Brilliant Blue R-250, 30\% MetOH/10\% acetic acid for $1 \mathrm{~h}$ and destained in $30 \%$ $\mathrm{MetOH} / 10 \%$ acetic acid. The digestion bands were analyzed using ImageJ software.

Table 1 Sequences of primers used for Real-Time PCR

\begin{tabular}{lll}
\hline & Forward $\mathbf{5}^{\prime}-\mathbf{3}^{\prime}$ & Reverse $\mathbf{5}^{\prime} \mathbf{-} \mathbf{3}^{\prime}$ \\
\hline Gapdh & ACACCCACTCCTCCACCTTT & TCCACCACCCTGTTGCTGTA \\
Mmp-2 & GCGGCGGTCACAGCTACTT & CACGCTCTTCAGACTTTGGTTCT \\
\hline
\end{tabular}

\section{Western blotting}

After $24 \mathrm{~h}$ of treatment, cells were lysed in a buffer (50 mM Tris- $\mathrm{HCl} \mathrm{pH} 5.5,150 \mathrm{mM} \mathrm{NaCl}$, Triton X-100 $0.5 \%)$ added with a complete protease inhibitor (Roche Applied Science). Equal amounts of proteins were denatured at $100{ }^{\circ} \mathrm{C}$ for $10 \mathrm{~min}$ and subjected to SDS-PAGE on $10 \%$ polyacrylamide gel. After the run, the proteins were electro-transferred on nitrocellulose membranes. Saturation of non-specific sites was performed for $2 \mathrm{~h}$ at room temperature in $5 \%$ milk in the TBST buffer (50 mM Tris- $\mathrm{HCl}, \mathrm{pH} 7.4,150 \mathrm{mM} \mathrm{NaCl}, 0.1 \%$ Tween 20). The membranes were exposed to primary antibodies directed against GAPDH (Santa Cruz sc-25778), $\alpha$-SMA (Sigma A5228), VIMENTIN (VIM) (Santa Cruz 7557), FIBRONECTIN (FN) (Santa Cruz sc-9068) overnight at $4{ }^{\circ} \mathrm{C}$ and subsequently incubated with a secondary antibody conjugated with peroxidase for $1 \mathrm{~h}$ at room temperature. The signal was detected with Luminata ${ }^{\mathrm{TM}}$ Forte Western HRP Substrate (Millipore) according to the manufacturer's instructions and the signal was acquired with Mini HD9 (UVItec, Cambridge). The band intensities were quantified using the UVItec Image Program.

\section{Immunofluorescence}

Both cell types, treated as described above, were seeded in CultureSlides (Falcon) to analyze the expression of $\alpha$-SMA, VIM proteins and stress fibers. These cells, fixed in $4 \%$ paraformaldehyde and permeabilized, were incubated overnight at $4{ }^{\circ} \mathrm{C}$ in PBS with $1 \%$ bovine serum albumin (BSA) with the primary antibodies directed against $\alpha$-SMA (1A4, Sigma) and VIM (Santa Cruz 7557). Then, the cells were washed with PBS prior to incubation for $1 \mathrm{~h}$ at room temperature with secondary antibodies (Goat anti-mouse IgG Alexa Fluor 546, Donkey antigoat IgG Alexa Fluor 488) in 1\% PBS/BSA. Cytoskeleton was visualized with phalloidin-TRITC (P1951, SigmaAldrich). The nuclei were marked with Hoechst 33258. A LeicaSP5 confocal microscope acquired the images. Exposure times and illumination intensity were the same for all the images.

\section{Oil Red O staining}

Cells were seeded in CultureSlides (Falcon), cultured to sub-confluence treated as described previously and fixed in $4 \%$ paraformaldehyde. Fixed cells were incubated with Oil Red O working solution for $1 \mathrm{~h}$, then cells were washed in PBS. Nuclei were counterstained with eosin.

\section{Statistical analysis}

Mean \pm S.D. of the real-time PCR data were calculated with Rest2009 software. Differences between control (CTR) and TGF- $\beta$ or IL-1 $\beta$ treated cells or between 
pre- and post-treatment with Canakinumab, were compared using two-tailed Student's t-test by $\mathrm{R}$ software (version 3.5.1). A p-value $<0.05$ was set as the level of significance for all tests.

\section{Results}

Effects of IL-1 $\beta$ inhibition on EMT of renal proximal tubular epithelial cells (HK-2)

To evaluate the potential anti-fibrotic effect of the IL-1 $\beta$ inhibitor, Canakinumab (CANAK), we measured by western blotting the protein level of three well-known EMT markers in HK- 2 cells exposed to TGF- $\beta$ or IL- $1 \beta$ in presence or absence of this agent.

In HK- 2 cells, IL- $1 \beta$ caused a significant increase in FN, VIM, and $\alpha$-SMA levels, comparable to those induced by TGF- $\beta$ (used as a control) (Fig. 1a-c). The addition of the CANAK prevent this effect. Interestingly, its protective effect also occurred in the presence of TGF- $\beta$.

Immunofluorescence experiments performed on HK-2 under the same conditions confirmed that IL-1 $\beta$ and TGF- $\beta$ increased the protein expression of VIM and $\alpha$-SMA. Phalloidin staining revealed that IL- $1 \beta$ and TGF- $\beta$ reduced the pool of junctional actin fibers and increased the stress fiber formation (Fig. 1d). The addition of Canakinumab inhibited the above-described effects.

\section{HK-2 cells migration in presence of IL-1 $\beta$}

To confirm the ability of renal tubular epithelial cells to migrate through the basal membrane into the interstitium (prerogative effect of EMT), we performed a cell motility assay. As expected, we demonstrated that IL-1 $\beta$ (similarly to TGF- $\beta$, used as a control) significantly increased the motility of HK2 cells (Fig. 2) confirming a possible differentiation toward a mesenchymal phenotype. Canakinumab inhibited this effect also when mediated by TGF- $\beta$.

\section{Metalloproteinase-2 regulation in HK-2 cells}

To clarify the role of IL-1 $\beta$ as inducer of EMT and to underline the anti-fibrotic effect of Canakinumab, we measured by Real-Time PCR the gene expression of a well-known EMT mediator responsible for extracellular matrix accumulation during fibrosis: $M m p-2$. The results of our experiments clearly showed that IL- $1 \beta$ increases the gene expression of $M m p-2$ (Fig. 3a). Interestingly, we found that this cytokine has no effect on Mmp-9 gene transcription levels (Additional file 1: Figure S1), according to previous studies [43, 44].

To confirm the inhibitory effects of IL-1 $\beta$ on MMP2 , we evaluated its enzymatic activity by zymography. Results showed that IL-1 $\beta$ (similarly to TGF- $\beta$ ) induced a significant increase in the MMP-2 enzymatic activity of this metalloproteinase. Contrarily, the presence of the Canakinumab prevented this effect (Fig. 3b, c). Although IL-1 $\beta$ has no effect on Mmp-9 gene expression, the zymography revealed an increment in its activity hampered by Canakinumab (Additional file 1: Figure S2).

\section{Effect of the IL-1 $\beta$ inhibition on the expression of EMT markers in hepatic stellate cells (LX-2)}

To validate the results obtained in renal cells and to clarify the pro-fibrotic role of this cytokine in liver, a highly prevalent condition with a great clinical impact, we performed in vitro experiments by employing hepatic stellate cells (LX-2).

Similarly to HK-2, we evaluated the impact of IL- $1 \beta$ and TGF- $\beta$ to up-regulate EMT markers ( $\alpha$-SMA, VIM and FN) and the inhibitory potential of Canakinumab.

Western blot analysis revealed that IL- $1 \beta$ was able to induce (similar to TGF- $\beta$ ) an over-expression of all the above-mentioned markers and the presence of Canakinumab inhibited these pro-fibrotic effects (Fig. 4a-c). As a further confirmation of these results, we performed immunofluorescence experiments for Phalloidin, VIM and $\alpha$-SMA in cells treated with IL- $1 \beta$ and Canakinumab obtaining similar results (Fig. $4 \mathrm{~d}$ ).

\section{Metalloproteinases expression/activity in LX-2 cells}

Similarly to HK2 cells, in LX-2 the administration of IL- $1 \beta$ was able to increase metalloproteinase 2 (Fig. $5 \mathrm{a}$ ) at gene expression level. Instead, Canakinumab maintained mRNA levels of this metalloprotease at levels comparable to controls (Fig. 5a). Likewise mRNA level of Mmp- 9 was augmented by IL- $1 \beta$ and Canakinumab prevent this effect (Additional file 1: Figure S3).

Additionally, similarly to HK-2, the enzymatic activity of MMP- 2 after IL- $1 \beta$ and TGF- $\beta$ stimulation was increased compared to controls. Canakinumab treatment inhibited this effect (Fig. 5b, c). MMP-9 activity was not detectable in this cell line (Additional file 1: Figure S4).

\section{Activation of LX-2 cells after Canakinumab}

Since the number and size of lipid droplets are inversely correlated with the activation status of LX-2 (31), we have analyzed the role of Canakinumab in reducing the lipid droplets content of LX-2. Staining with Oil Red O revealed an increase in the number of lipid droplets after treatment with Canakinumab (Fig. 6). This phenomenon suggests that the inhibition of IL- $1 \beta$ leads LX- 2 cells into a quiescent state. 


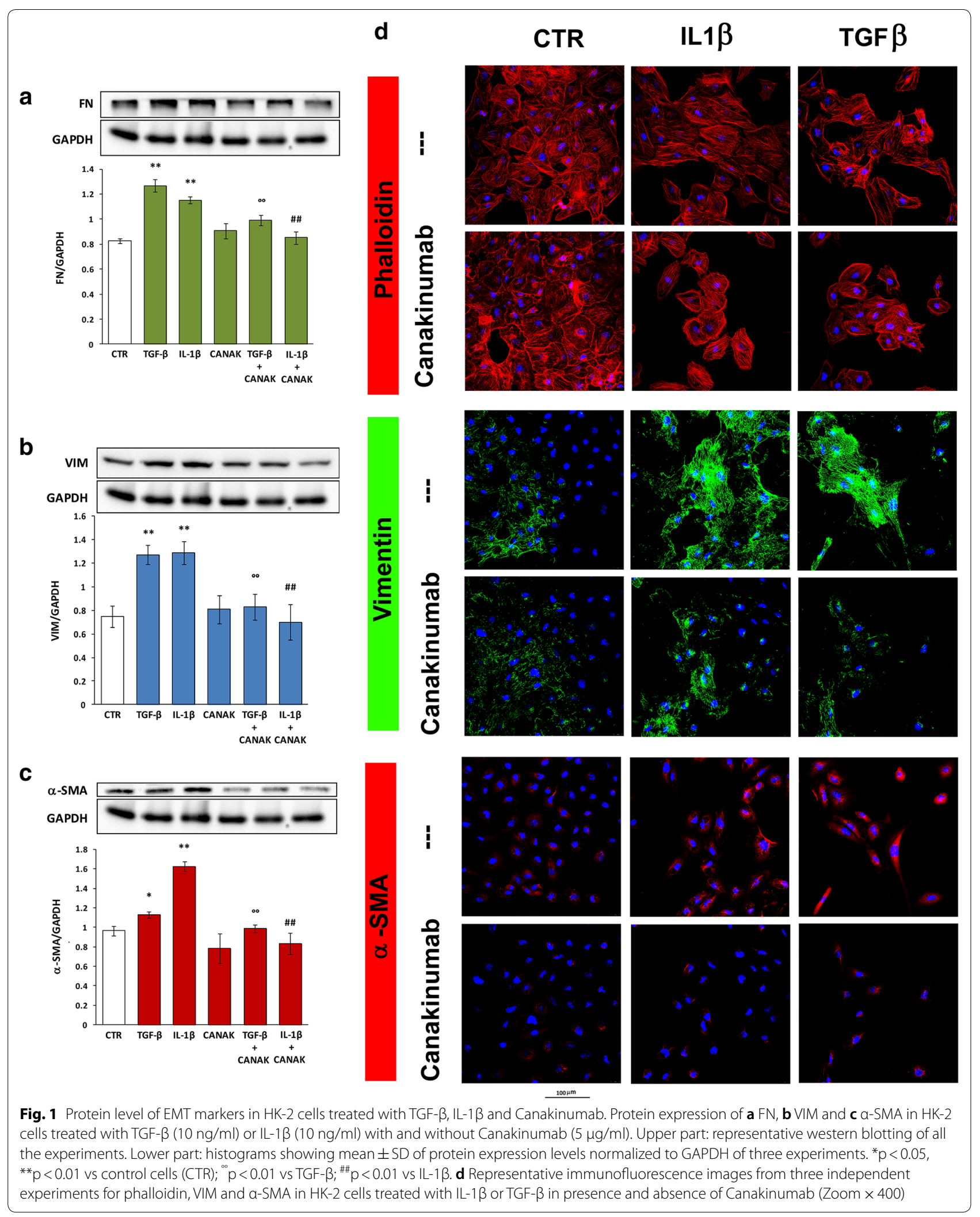




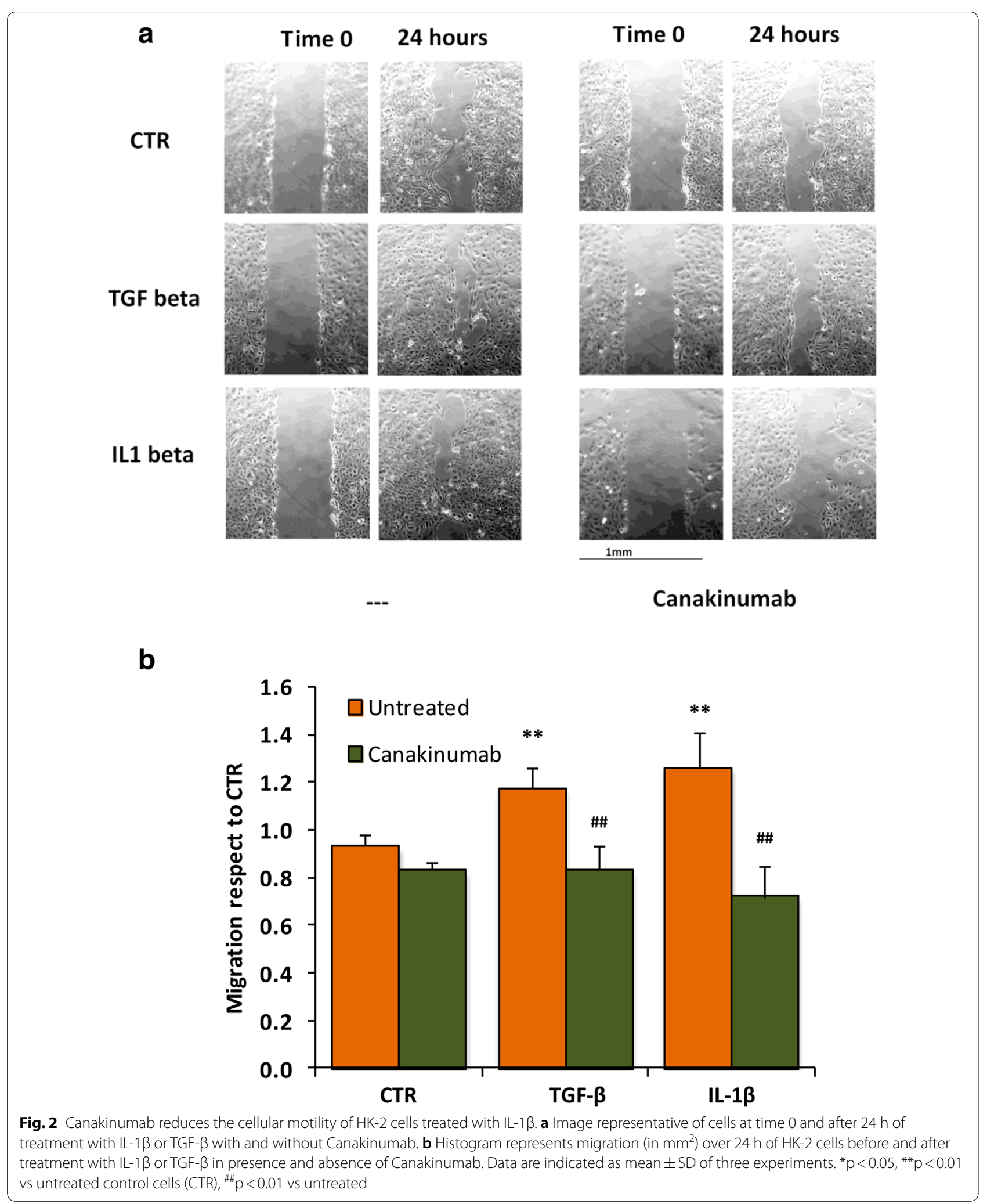



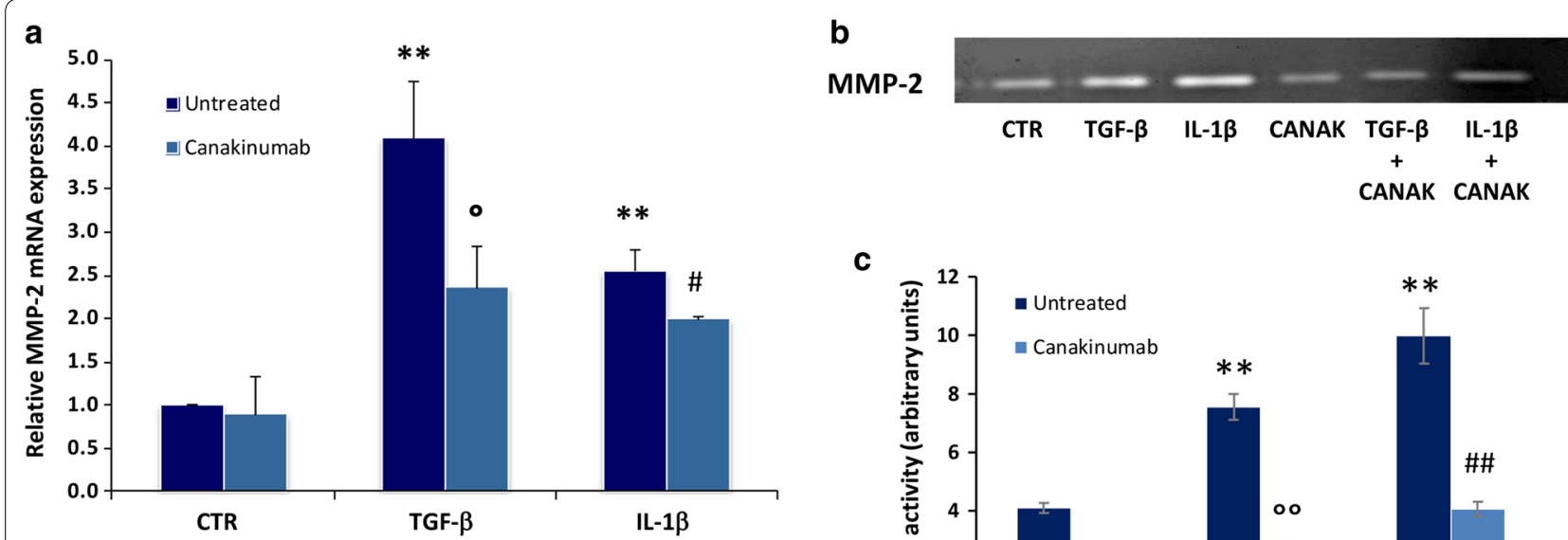

C

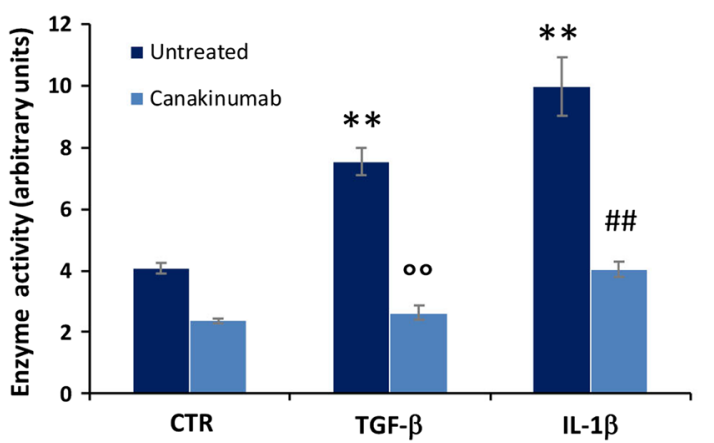

Fig. 3 Canakinumab reduces Mmp-2 expression and enzymatic activity induced by IL-1 $\beta$ in HK-2 cells. a Gene expression of Mmp-2 measured by Real Time-PCR in HK-2 cells treated with IL-1 $\beta$ or TGF- $\beta$ with and without Canakinumab. Expression levels are normalized to Gapdh. Data are indicated as mean \pm SD of three experiments performed in triplicate. $\mathbf{b}$ Gelatin zymography shows the activity of MMP-2 in the conditioned media of HK-2 cells treated for $24 \mathrm{~h}$ with TGF- $\beta(10 \mathrm{ng} / \mathrm{ml})$ or $\mathrm{lL}-1 \beta(10 \mathrm{ng} / \mathrm{ml})$ in the presence or absence of Canakinumab $(5 \mu \mathrm{g} / \mathrm{ml})$. c The histogram represents the densitometric analysis of enzymatic activity of MMP- 2 as a mean \pm SD of three experiments. The $p$ value was calculated with the t-test. ${ }^{* *} p<0.001$ versus untreated control cells (CTR); $p<0.05,{ }^{\circ} p<0.01$ vs TGF- $\beta$ untreated; $\#<0.05, \# \#<0.01$ vs IL-1 $\beta$ untreated

\section{Discussion}

In the last few years, many authors have studied the mechanisms underlying the trans-differentiation of epithelial cells to a mesenchymal phenotype and searched for therapeutic agents able to minimize this process. In fact, it is known that the progression of chronic organ damage and, in particular, the development of chronic renal and hepatic disease represent an important public health problem.

In literature, it is widely described that in both kidney and liver, EMT is an active process that occurs through the loss of the epithelial phenotype of many cellular subsets with the over-expression of specific mesenchymal surface markers, such as vimentin and $\alpha$-smooth muscle actin [3].

In addition, because of the cytoskeletal remodelling and release of matrix metalloproteases with consequent basal membrane degradation, cells with acquired myofibroblastic phenotype are able to migrate into the interstitium, where they can play a key role in the pathogenic process leading to chronic renal damage [1]. These processes could also represent important determinants of the metastatic capacity of tumor cells.

Among the biological/biochemical elements inducing EMT there are several growth factors, integrins and cytokines such as TNF- $\alpha$, IL-4, IL-13 and IL- $1 \beta$. In particular, the role of IL-1 $\beta$ and its receptor (IL-1R) targeting agents in renal and hepatic fibrosis has been evaluated in a few animal model studies. In particular, in models of glomerulonephritis and unilateral ureteral obstruction, the administration of a specific IL-1R antagonist was able to inhibit the progression of functional damage and almost completely abrogated interstitial fibrosis/tubular atrophy (IF/TA) [25-27].

Similarly, in mouse models of liver injury, IL-1R antagonist or silencing caused a reduction in laminin and collagen deposition in the tissue and a reduction of inflammatory infiltrate compared to untreated or wild type animals [31, 34].

Therefore, to confirm the role of IL-1 $\beta$ in the kidney and liver and to analyze, for the first time, the potential protective effect of Canakinumab, a monoclonal antibody targeting IL-1 $\beta$ currently used for the treatment of immune-inflammatory diseases (such as rheumatoid arthritis, systemic juvenile idiopathic arthritis, and syndromes associated with cryopyrin), we treated epithelial cells of the proximal renal tubule (HK-2) and hepatic stellate cells (LX-2) with this cytokine and subsequently measured EMT markers using various classical molecular biology techniques.

As expected, in both cell lines the IL- $1 \beta$ stimulus determined a specific phenotypic change towards a mesenchymal type. Furthermore, inhibition with Canakinumab minimized this pro-fibrotic effect.

Our results, on the other hand, clearly showed for the first time the anti-fibrotic role of Canakinumab 


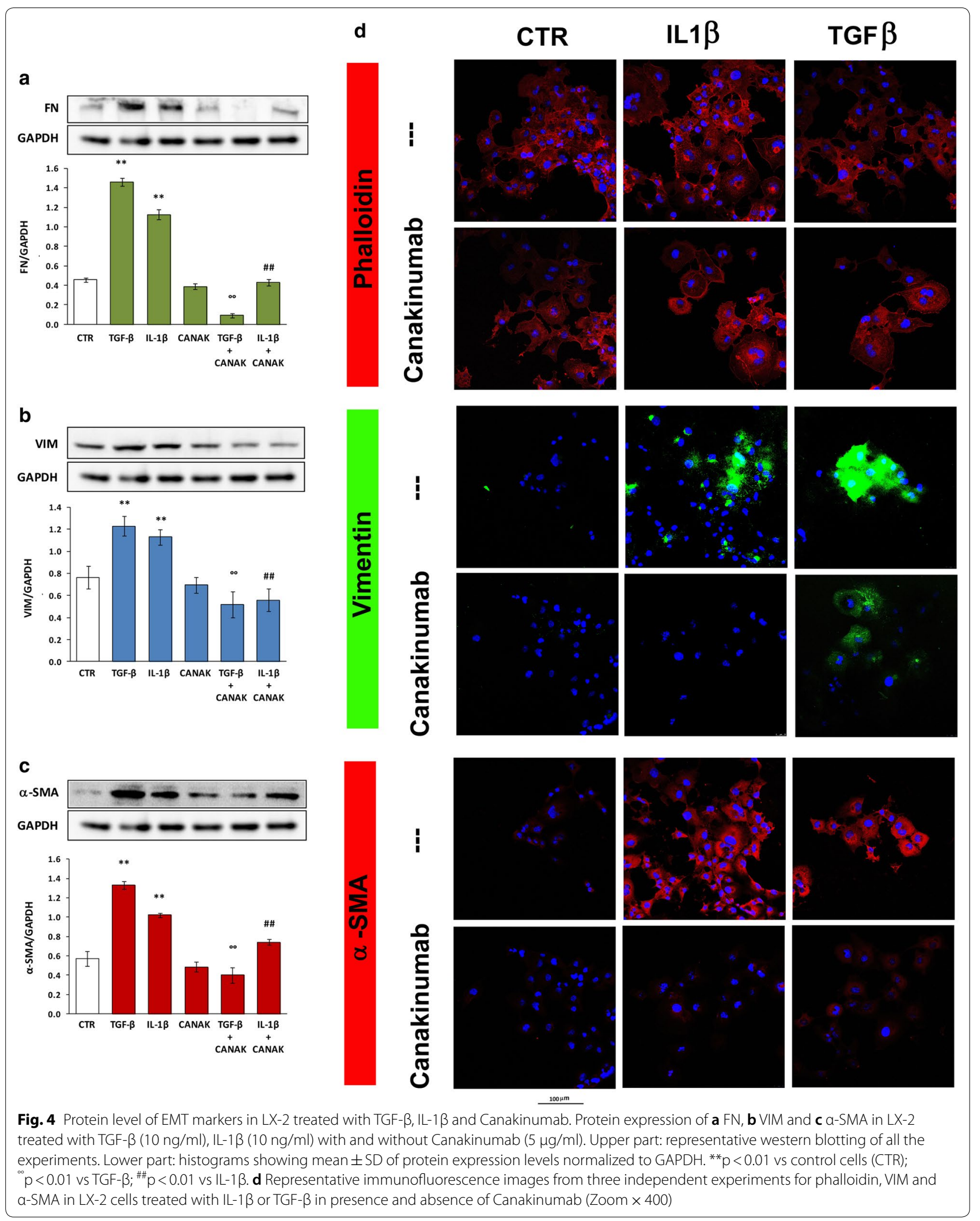




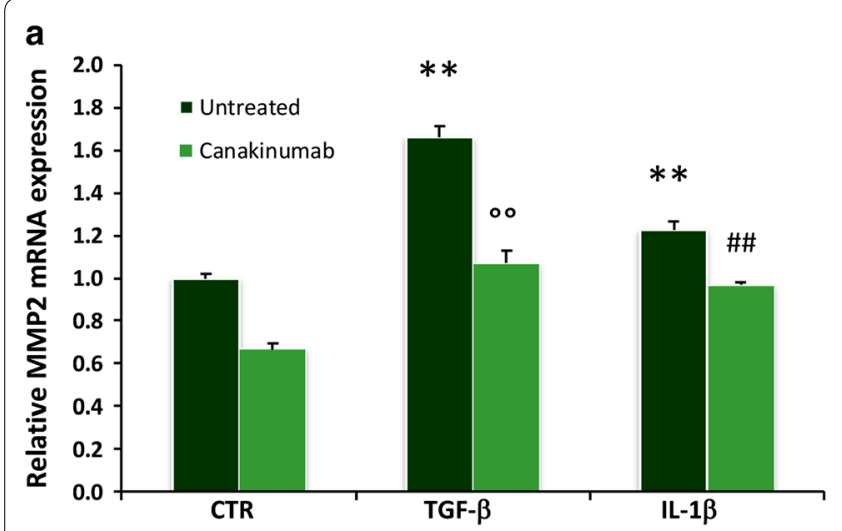

b

MMP2

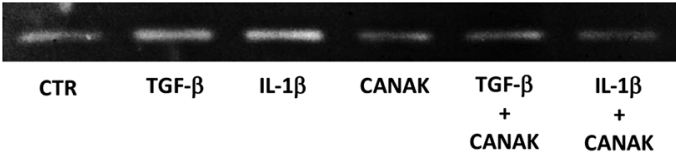

C

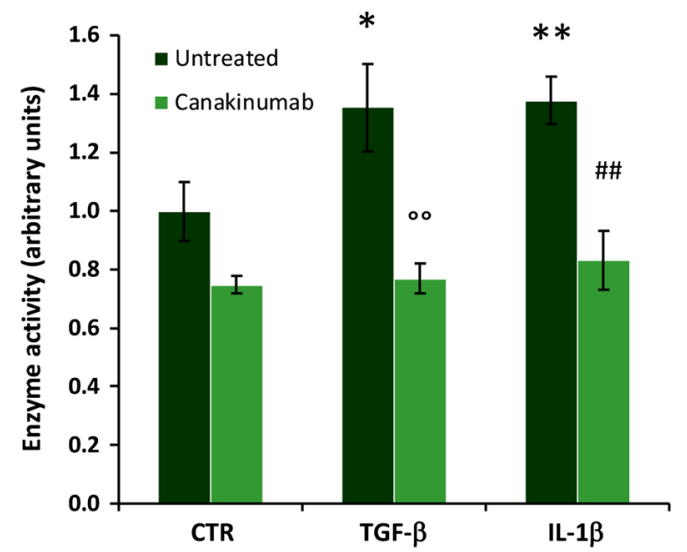

Fig. 5 Canakinumab reduces MMP-2 expression and enzymatic activity induced by IL-1 $\beta$ in LX-2 cells. a Gene expression of Mmp-2 evaluated by Real-Time PCR in LX-2 cells treated with TGF- $\beta(10 \mathrm{ng} / \mathrm{ml}), \mathrm{L}-1 \beta(10 \mathrm{ng} / \mathrm{ml})$ in presence and absence of Canakinumab. Expression levels were normalized to Gapdh. Mean \pm SD of three different experiments performed in triplicate. $\mathbf{b}$ Gelatin zymography shows the activity of MMP-2 in the conditioned media of HK-2 cells treated for $24 \mathrm{~h}$ with TGF- $\beta(10 \mathrm{ng} / \mathrm{ml})$ or IL-1 $\beta(10 \mathrm{ng} / \mathrm{ml})$ in the presence or absence of Canakinumab $(5 \mu \mathrm{g} / \mathrm{ml})$. c Histogram represents the densitometry analysis of the enzymatic activity as a mean \pm SD of three experiments performed in triplicate. The $p$ value was calculated with the t-test. ${ }^{*} p<0.05,{ }^{* *} p<0.01$ versus untreated control cells (CTR); ${ }^{\circ} p<0.01$ vs TGF- $\beta$ untreated; ${ }^{\# \#} p<0.01$ vs IL-1 $\beta$ untreated
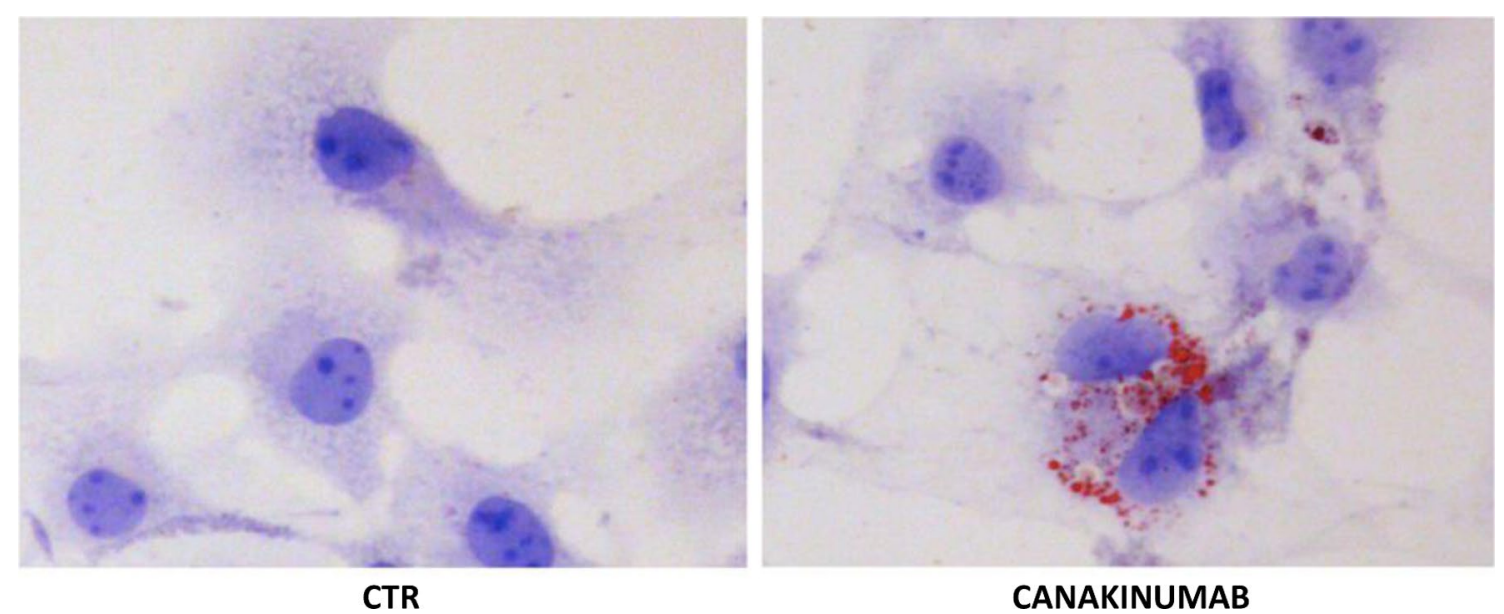

CANAKINUMAB

Fig. 6 Inactivation of HSCs by the Canakinumab. Staining with Oil Red O shows an increase in the content of lipid droplets in LX-2 cells treated with Canakinumab. The inhibition of IL-1 $\beta$ by Canakinumab promotes the inactivation of HSCs as demonstrated by the accumulation of lipid droplets in the cytoplasm. The images are representative of one of three experiments performed with Oil Red O staining

occurred on cells treated with TGF- $\beta$, a well-known inducer of EMT and fibrosis. This finding was in agreement with some literature data that reported a synergistic effect of IL-1 $\beta$ and TGF- $\beta$ in collagen deposition as well as in the FN accumulation in mesangial cells $[45,46]$.
Moreover, we found an interesting effect of IL-1 $\beta$ on the two most important matrix metalloproteases (MMP-2 and MMP-9) involved in organ fibrosis. In both cell lines, IL-1 $\beta$ increased expression and enzymatic activity of MMP-2. Interestingly in renal cells, although IL-1 $\beta$ had no effect on Mmp-9 gene expression, the 
zymography revealed an increment in its activity hampered by Canakinumab probably via a post-transcriptional modification mechanism. In contrast, in liver cells Canakinumab inhibited the up-regulation of Mmp-9 mRNA level but its enzymatic activity was not detectable. Although other authors have already observed this effect, the mechanism is not yet fully understood. It seems to involve the activation of several mitogen-activated protein kinases (MAPK). This is a family of serine/threonine kinases mediating cellular response to extracellular stimuli, such as stress, oncogenes, mitogens and inflammation, through regulation of gene expression, mitosis, metabolism, survival, proliferation and apoptosis $[43,44$, 47]. Further studies are needed to confirm these data and to clarify the mechanisms behind this different response.

Overall, our results illustrate new therapeutic applicability of antibodies targeted against IL- $1 \beta$, which is added to the well-described anti-inflammatory potential. In addition, they could prove to be good therapeutic weapons for chronic pro-fibrotic diseases.

In fact, Niccoli et al. have recently reported a beneficial effect of Canakinumab on a patient suffering from asbestosis, a progressive interstitial lung disease caused by inhalation of asbestos fibers that occurs in subjects longexposed to asbestos dust (miners, quarry workers, millers) [48]. It is plausible that this positive result was due to the anti-fibrotic role of this drug.

\section{Conclusions}

Therefore, in conclusion, our results showed, for the first time, that a pharmacological inhibition of IL-1 $\beta$ could inhibit the development of EMT in renal and hepatic cells and likely inhibits the genesis of chronic organ damage. Although burdened by the limits of an in vitro model, our study emphasizes the therapeutic potential of Canakinumab and further in vivo analyses will be necessary to better characterize this effect. In fact, in the future it is plausible that the pharmacological inhibition of this enzyme may represent a valid therapeutic tool to minimize renal and hepatic fibrosis, especially in transplanted organs from "extended criteria donors" or subjected to multiple pro-fibrotic stimuli.

\section{Additional file}

Additional file 1: Figure S1. Gene expression of Metalloproteinase-9 (Mmp-9) in HK-2. Figure S2. Enzymatic activity of MMP-9 in HK-2. Figure S3. Gene expression of Metalloproteinase-9 (Mmp-9) in LX-2. Figure S4. Enzymatic activity of MMP-9 in LX-2.
Authors' contributions

Conceptualization, VM, AC and GZ; methodology VM, SG, LS, GB; formal analysis GZ, PV, VM; data curation GZ, AC, MO; writing-original draft preparation, GZ, GG, LS; writing-review and editing, PV, AL, UT. All authors read and approved the final manuscript.

\section{Author details \\ ${ }^{1}$ Renal Unit, Department of Medicine, University-Hospital of Verona, Piaz- zale A. Stefani 1, 37126 Verona, VR, Italy. ${ }^{2}$ Department of General Surgery and Odontoiatrics, Liver Transplant Unit, University Hospital of Verona, Piazzale Stefani 1, 37126 Verona, Italy. ${ }^{3}$ Department of Biomedical Sciences, University of Padova, Via Ugo Bassi, 58/B, 35131 Padua, Italy. ${ }^{4}$ Division of Nephrology and Dialysis, School of Medicine, Columbus-Gemelli Hospital Catholic Univer- sity, Largo Agostino Gemelli 8, 00168 Rome, RM, Italy.}

\section{Acknowledgements}

Not applicable.

\section{Competing interests}

The authors declare that they have no competing interests.

\section{Availability of data and materials}

All data generated or analyzed during this study are included in this published article and its supplementary information file.

Consent for publication

Not applicable.

Ethics approval and consent to participate

Not applicable.

Funding

This work was supported by the grant from the Ministry of Health (GR-2011-02350438)

\section{Publisher's Note}

Springer Nature remains neutral with regard to jurisdictional claims in published maps and institutional affiliations.

Received: 29 August 2018 Accepted: 2 January 2019

Published online: 07 January 2019

References

1. Kalluri R, Weinberg RA. The basics of epithelial-mesenchymal transition. J Clin Invest. 2009;119(6):1420-8.

2. Kalluri R, Neilson EG. Epithelial-mesenchymal transition and its implications for fibrosis. J Clin Invest. 2003;112(12):1776-84.

3. Liu Y. Epithelial to mesenchymal transition in renal fibrogenesis: pathologic significance, molecular mechanism, and therapeutic intervention. J Am Soc Nephrol. 2004;15(1):1-12.

4. Thiery JP, Sleeman JP. Complex networks orchestrate epithelial-mesenchymal transitions. Nat Rev Mol Cell Biol. 2006;7(2):131-42.

5. Borthwick LA, Wynn TA, Fisher AJ. Cytokine mediated tissue fibrosis. Biochim Biophys Acta. 2013;1832(7):1049-60.

6. Lee K, Nelson CM. New insights into the regulation of epithelialmesenchymal transition and tissue fibrosis. Int Rev Cell Mol Biol. 2012;294:171-221.

7. Dinarello CA. Interleukin-1 and interleukin-1 antagonism. Blood. 1991;77(8):1627-52.

8. Piccioli P, Rubartelli A. The secretion of IL-1 $\beta$ and options for release. Semin Immunol. 2013;25(6):425-9.

9. Eder C. Mechanisms of interleukin-1 beta release. Immunobiology. 2009;214(7):543-53.

10. Sutterwala FS, Ogura Y, Szczepanik M, Lara-Tejero M, Lichtenberger GS, Grant EP, Bertin J, Coyle AJ, Galán JE, Askenase PW, Flavell RA. Critical role for NALP3/CIAS1/Cryopyrin in innate and adaptive immunity through its regulation of caspase-1. Immunity. 2006;24:317-27. 
11. Martinon F, Burns K, Tschopp J. The inflammasome: a molecular platform triggering activation of inflammatory caspases and processing of prolLbeta. Mol Cell. 2002;10(2):417-26.

12. Afonina IS, Müller C, Martin SJ, Beyaert R. Proteolytic processing of interleukin-1 family cytokines: variations on a common theme. Immunity. 2015;42(6):991-1004.

13. Joosten LA, Netea MG, Fantuzzi G, Koenders MI, Helsen MM, Sparrer H, Pham CT, van der Meer JW, Dinarello CA, van den Berg WB. Inflammatory arthritis in caspase 1 gene-deficient mice: contribution of proteinase 3 to caspase 1-independent production of bioactive interleukin-1beta. Arthritis Rheum. 2009;60(12):3651-62.

14. Fan JM, Huang XR, Ng YY, Nikolic-Paterson DJ, Mu W, Atkins RC, Lan HY. Interleukin-1 induces tubular epithelial-myofibroblast transdifferentiation through a transforming growth factor-beta1-dependent mechanism in vitro. Am J Kidney Dis. 2001;37(4):820-31.

15. Vesey DA, Cheung CW, Cuttle L, Endre ZA, Gobé G, Johnson DW. Interleukin-1beta induces human proximal tubule cell injury, alphasmooth muscle actin expression and fibronectin production. Kidney Int. 2002;62(1):31-40.

16. Lonnemann G, Shapiro L, Engler-Blum G, Müller GA, Koch KM, Dinarello CA. Cytokines in human renal interstitial fibrosis. I. Interleukin-1 is a paracrine growth factor for cultured fibrosis-derived kidney fibroblasts. Kidney Int. 1995;47(3):837-44.

17. Vesey DA, Cheung C, Cuttle L, Endre Z, Gobe G, Johnson DW. Interleukin1 beta stimulates human renal fibroblast proliferation and matrix protein production by means of a transforming growth factor-beta-dependent mechanism. J Lab Clin Med. 2002;140(5):342-50.

18. Lonnemann G, Engler-Blum G, Müller GA, Koch KM, Dinarello CA. Cytokines in human renal interstitial fibrosis. II. Intrinsic interleukin (IL)-1 synthesis and IL-1-dependent production of IL- 6 and IL- 8 by cultured kidney fibroblasts. Kidney Int. 1995;47(3):845-54.

19. Matsumoto K, Dowling J, Atkins RC. Production of interleukin 1 in glomerular cell cultures from patients with rapidly progressive crescentic glomerulonephritis. Am J Nephrol. 1988;8(6):463-70.

20. Noronha IL, Krüger C, Andrassy K, Ritz E, Waldherr R. In situ production of TNF-alpha, IL-1 beta and IL-2R in ANCA-positive glomerulonephritis. Kidney Int. 1993;43(3):682-92.

21. Yoshioka K, Takemura T, Murakami K, Okada M, Yagi K, Miyazato H, Matsushima K, Maki S. In situ expression of cytokines in IgA nephritis. Kidney Int. 1993:44(4):825-33.

22. Boswell JM, Yui MA, Burt DW, Kelley VE. Increased tumor necrosis factor and IL-1 beta gene expression in the kidneys of mice with lupus nephritis. J Immunol. 1988;141(9):3050-4.

23. Matsumoto K, Atkins RC. Glomerular cells and macrophages in the progression of experimental focal and segmental glomerulosclerosis. Am J Pathol. 1989;134(4):933-45.

24. Tesch GH, Yang N, Yu H, Lan HY, Foti R, Chadban SJ, Atkins RC, NikolicPaterson DJ. Intrinsic renal cells are the major source of interleukin-1 beta synthesis in normal and diseased rat kidney. Nephrol Dial Transplant. 1997;12(6):1109-15.

25. Lan HY, Nikolic-Paterson DJ, Zarama M, Vannice JL, Atkins RC. Suppression of experimental crescentic glomerulonephritis by the interleukin-1 receptor antagonist. Kidney Int. 1993:43(2):479-85.

26. Lan HY, Nikolic-Paterson DJ, Mu W, Vannice JL, Atkins RC. Interleukin-1 receptor antagonist halts the progression of established crescentic glomerulonephritis in the rat. Kidney Int. 1995;47(5):1303-9.

27. Chen A, Sheu LF, Chou WY, Tsai SC, Chang DM, Liang SC, Lin FG, Lee WH. Interleukin-1 receptor antagonist modulates the progression of a spontaneously occurring IgA nephropathy in mice. Am J Kidney Dis. 1997;30(5):693-702.

28. Jones LK, O'Sullivan KM, Semple T, Kuligowski MP, Fukami K, Ma FY, Nikolic-Paterson DJ, Holdsworth SR, Kitching AR. IL-1RI deficiency ameliorates early experimental renal interstitial fibrosis. Nephrol Dial Transplant. 2009;24(10):3024-32.

29. Gieling RG, Wallace K, Han YP. Interleukin-1 participates in the progression from liver injury to fibrosis. Am J Physiol Gastrointest Liver Physiol. 2009;296(6):G1324-31.
30. Miura K, Kodama Y, Inokuchi S, Schnabl B, Aoyama T, Ohnishi H, Olefsky JM, Brenner DA, Seki E. Toll-like receptor 9 promotes steatohepatitis by induction of interleukin-1 beta in mice. Gastroenterology. 2010;139(1):323-.

31. Petrasek J, Bala S, Csak T, Lippai D, Kodys K, Menashy V, Barrieau M, Min SY, Kurt-Jones EA, Szabo G. IL-1 receptor antagonist ameliorates inflammasome-dependent alcoholic steatohepatitis in mice. J Clin Invest. 2012;122(10):3476-89.

32. Yan C, Zhou L, Han YP. Contribution of hepatic stellate cells and matrix metalloproteinase 9 in acute liver failure. Liver Int. 2008;28(7):959-71.

33. Pradere JP, Kluwe J, De Minicis S, Jiao JJ, Gwak GY, Dapito DH, Jang MK, Guenther ND, Mederacke I, Friedman R, Dragomir AC, Aloman C, Schwabe RF. Hepatic macrophages but not dendritic cells contribute to liver fibrosis by promoting the survival of activated hepatic stellate cells in mice. Hepatology. 2013;58(4):1461-73.

34. Mancini R, Benedetti A, Jezequel AM. An interleukin-1 receptor antagonist decreases fibrosis induced by dimethylnitrosamine in rat liver. Virchows Arch. 1994;424(1):25-31.

35. Federici S, Martini A, Gattorno M. The central role of anti-IL-1 blockade in the treatment of monogenic and multi-factorial autoinflammatory diseases. Front Immunol. 2013;4:351.

36. Dhimolea E. Canakinumab. MAbs. 2010;2(1):3-13.

37. Rogliani P, Calzetta L, Ora J, Matera MG. Canakinumab for the treatment of chronic obstructive pulmonary disease. Pulm Pharmacol Ther. 2015;31:15-27.

38. Giancane G, Minoia F, Davì S, Bracciolini G, Consolaro A, Ravelli A. IL-1 inhibition in systemic juvenile idiopathic arthritis. Front Pharmacol. 2016;7:467.

39. Ridker PM, Everett BM, Thuren T, MacFadyen JG, Chang WH, Ballantyne C, Fonseca F, Nicolau J, Koenig W, Anker SD, Kastelein JJP, Cornel JH, Pais P, Pella D, Genest J, Cifkova R, Lorenzatti A, Forster T, Kobalava Z, Vida-Simiti L, Flather M, Shimokawa H, Ogawa H, Dellborg M, Rossi PRF, Troquay RPT, Libby P, Glynn RJ, CANTOS Trial Group. Antiinflammatory therapy with canakinumab for atherosclerotic disease. N Engl J Med. 2017;377(12):1119-31.

40. Alten R, Gram H, Joosten LA, van den Berg WB, Sieper J, Wassenberg S, Burmester G, van Riel P, Diaz-Lorente M, Bruin GJ, Woodworth TG, Rordorf C, Batard Y, Wright AM, Jung T. The human anti-IL-1 beta monoclonal antibody ACZ885 is effective in joint inflammation models in mice and in a proof-of-concept study in patients with rheumatoid arthritis. Arthritis Res Ther. 2008;10(3):R67.

41. Bonnemaison ML, Marks ES, Boesen El. Interleukin-1 $\beta$ as a driver of renal NGAL production. Cytokine. 2017;91:38-43.

42. Zhang M, Tang J, Li X. Interleukin-1 beta-induced transdifferentiation of renal proximal tubular cells is mediated by activation of JNK and p38 MAPK. Nephron Exp Nephrol. 2005;99(3):e68-76.

43. Nee LE, MCMorrow T, Campbell E, Slattery C, Ryan MP. TNF-alpha and IL-1 beta-mediated regulation of MMP-9 and TIMP-1 in renal proximal tubular cells. Kidney Int. 2004;66(4):1376-86.

44. Nee L, Tuite N, Ryan MP, McMorrow T. TNF-alpha and IL-1 beta-mediated regulation of MMP-9 and TIMP-1 in human glomerular mesangial cells. Nephron Exp Nephrol. 2007;107(2):e73-86.

45. Leung LY, Tian D, Brangwynne CP, Weitz DA, Tschumperlin DJ. A new microrheometric approach reveals individual and cooperative roles for TGF-beta 1 and IL-1 $\beta$ eta in fibroblast-mediated stiffening of collagen gels. FASEB J. 2007;21(9):2064-73.

46. Pawluczyk IZ, Harris KP. Cytokine interactions promote synergistic fibronectin accumulation by mesangial cells. Kidney Int. 1998;54(1):62-70.

47. Cargnello M, Roux PP. Activation and function of the MAPKs and their substrates, the MAPK-activated protein kinases. Microbiol Mol Biol Rev. 2011;75(1):50-83.

48. Niccoli L, Cassarà E, Kaloudi O, Nannini C, Romagnoli M, Cantini F. Systemic autoimmune disease in asbestosis rapidly responding to antiinterleukin-1 beta antibody canakinumab: a case report. BMC Musculoskelet Disord. 2015;16:146. 